\title{
Continuous ventricular cerebrospinal fluid drainage with intracranial pressure monitoring for management of posttraumatic diffuse brain swelling
}

\author{
Almir Ferreira de Andrade, Wellingson Silva Paiva, \\ Robson Luis Oliveira de Amorim, Eberval Gadelha Figueiredo, \\ Antonio Nogueira de Almeida, Roger Schmidt Brock, \\ Edson Bor-Seng-Shu, Manoel Jacobsen Teixeira
}

\begin{abstract}
Background: Ventricular drainage has played an important role in the management of traumatic brain-injured patients. The aim of the present study was describe outcomes in a series of 57 patients with diffuse brain swelling underwent to intracranial pressure (ICP) monitoring. Method: Fifty-eight patients with diffuse posttraumatic brain swelling, were evaluated prospectively. The Glasgow Coma Scale (GCS) scores of patients varied from 4 to 12. Patients groups divided according to GCS and age. Patient neurological assessment was classified as favorable, unfavorable, and death. Results: Mechanisms of injury were vehicle accidents in $72.4 \%$ and falls in $15.6 \%$. $54 \%$ of patients had GCS scores between 6 and 8 . There were no statistical differences, regarding outcome, between groups separated by age. In the adults group ( $n=47), 44.7 \%$ evolved favorably. Conclusion: Our results indicate a poor prognosis in patients with brain swelling. We believe that continuous ventricular CSF drainage with ICP monitoring is a simple method as an adjunct in the management of these patients.
\end{abstract}

Key words: decompressive craniectomy, intracranial pressure monitoring, head injury, brain swelling.

Drenagem contínua de líquido cefalorraquidiano com monitoração intermitente de pressão intracraniana em pacientes com tumefação cerebral difusa pós-traumática

\section{RESUMO}

Introdução: Monitoração da pressão intracraniana (PIC) tem desempenhado um papel importante nos pacientes com lesão cerebral difusa traumática. O objetivo do presente estudo foi descrever os resultados de uma série de 57 pacientes com tumefação cerebral difusa submetidos à monitoração da PIC. Método: Cinquenta e oito pacientes com lesão axonal difusa foram avaliados prospectivamente. Na Escala de Coma de Glasgow (GCS) os escores variaram de 4 a 12. Os grupos de pacientes, foram divididos de acordo com a GCS e a idade. Avaliação neurológica tardia foi classificada como favorável, desfavorável, e da morte. Resultados: Mecanismos de lesão predominantes foram os acidentes de veículos em $72,4 \%$ e quedas em $15,6 \% ; 54 \%$ dos pacientes tiveram escores GCS entre 6 e 8 . Não houve diferença estatística entre os grupos separados por idade. No grupo de adultos ( $n=47), 44,7 \%$ evoluíram favoravelmente. Conclusão: As lesões difusas tipo III apresentam

Correspondence

Wellingson Silva Paiva

Rua Teodoro Sampaio 498/66

05406-000 São Paulo SP - Brasil

E-mail: wellingsonpaiva@yahoo.com.br

Received 17 February 2010

Received in final form 12 June 2010

Accepted 21 June 2010 resultados funcionais desfavoráveis. Acreditamos que a monitoração intermitente de PIC com drenagem de líquido cefalorraquidiano seja um método simples e aplicável no apoio ao tratamento destes pacientes

Palavras-chave: traumatismo craniocerebral, líquido cefalorraquidiano, lesão axonal.

Department of Neurology and Neurosurgery, Clinical's Hospital, University of São Paulo Medical School, São Paulo SP, Brazil. 
Management of posttraumatic brain swelling is still a challenge in contemporary neurosurgery and critical care medicine. According to Traumatic Coma Data Bank (TCDB), 83\% of patients who present traumatic brain swelling have unfavorable outcome ${ }^{1}$. Mortality rate reach $77 \%, 39 \%$, and $22 \%$, among those with absent, compressed, and normal basal cisterns respectively ${ }^{2}$. Pathophysiology of this condition remains poorly understood, and, as a consequence, results of its treatment are disappointing. Although it has been demonstrated that decompressive craniectomy may improve cerebral hemodynamics in patients presenting intracranial hypertension associated with severe brain swelling ${ }^{3}$, its clinical efficacy regarding outcome has not been established so far and complications have been related to this method ${ }^{4}$. Furthermore, clear-cut indications for performing such a procedure have not yet been delineated. Today there are several invasive methods to monitor intracranial pressure $(\mathrm{ICP})^{5-7}$. However, use of an intraventricular catheter is the only method which permits both ICP control, by draining cerebrospinal fluid (CSF), and ICP monitoring. Furthermore, authors have suggested that patients submitted to continuous CSF drainage may present better outcome and lower levels of $\mathrm{ICP}^{8-11}$ and, an increase in the clearance of CSF proinflammatory substances related to the traumatic event may be expected and it may represent an advantage of this method ${ }^{12}$.

We have routinely used continuous ventricular CSF drainage with ICP monitoring in diffuse posttraumatic brain swelling since 2000. The purpose of this study is to present our experience in the use of continuous ventricular CSF drainage with intermittent ICP monitoring in the management of posttraumatic bihemispheric brain swelling.

\section{METHOD}

Procedures performed in this study were approved by the ethical committee of our hospital. Preoperative medical management followed guidelines of the American College of Surgeons (Advanced Trauma Life Support $)^{13}$, and the Brazilian Society of Neurosurgery. After stabilization of respiratory and systemic hemodynamic parameters, patients who had developed neurological abnormality underwent brain computerized tomography (CT) scans.

Fifty-eight patients admitted at the Clinical's Hospital of University of São Paulo Medical School met the inclusion criteria and were evaluated prospectively in five years. They suffered traumatic brain injury and sustained Glasgow Coma Scale (GCS) 4-12 points for a period over six hours. The (CT) scans disclosed diffuse brain swelling. Basal cisterns were absent or compressed with midline shift of 0 to $5 \mathrm{~mm}$, no high- or mixed-density lesion greater than $25 \mathrm{~cm}$ was found (Diffuse Injury type III) ${ }^{14}$. The Glasgow Coma Scale score varied from 4 to 12 . Patients not treated postoperatively in an intensive care unit were not included in this study.

Thirteen patients presented intracranial lesion with mass effect ( 1 epidural hematoma, 6 subdural hematomas, 3 epidural and subdural hematomas, and 3 with gunshot injuries). They were taken to the operating room immediately after the diagnosis. In these cases, the decision of monitoring was based on postoperative CT scan results. Patients were divided into three groups according to the GCS scores obtained previously to ICP monitoring. Group 1 included patients with scores from 4 to 5 , group 2 included scores from 6 to 8 , and group 3 scores from 9 to 12. Patients were also grouped by age in pediatric (younger than 17 years old) and adult (17 years old or older).

ICP quantitative values and complications related to ventricular catheterization and ICP monitoring, such as infections and hemorrhages, were noted down. Infection was diagnosed by a CSF pleocytosis, positive culture, or hypoglicorraquia associated with clinical signs of infec$\operatorname{tion}^{15}$. Patient neurological assessment at hospital discharge was classified as favorable (able to care for self), unfavorable (unable to care for self), and death.

\section{ICP monitoring technique}

The procedure was carried out in the operating room. Parameters of catheter implantation were based on previous report ${ }^{16}$. Linear incision was performed, under general anesthesia, just $1.0 \mathrm{~cm}$ anterior to the coronal and $3.0 \mathrm{~cm}$ lateral to the sagital suture. Catheters (external unidirectional flow catheter, Ventura ${ }^{\circ}$, São José do Rio Preto, SP - Brazil) were positioned in the frontal horn and connected to a hydrostatic system. Overall, successful catheterization was achieved in no more than three attempts (Figs 1 and 2). The hydrostatic system was connected to a one-way valve with two outlets, one for a collector bag and other for an external microtransducer connected to the monitor (Dixtal, Manaus, AM, Brasil). The drainage system was calibrated at $10 \mathrm{mmHg}$ over the foramen of Monro, after calibration in $10 \mathrm{mmHg}$, the EVD system was kept open for 45 minutes with continuous drainage for 15 minutes, the closing being performed every hour to monitor ICP. Continuous CSF passage was allowed when ICP had overcome this value.

ICP values were measured intermittently three times a day or whenever clinically necessary. ICP values up to $20 \mathrm{mmHg}$ were considered abnormal. After catheter insertion, patients were taken to intensive care unit. General and specific procedures to keep ICP and brain perfusion under control were based on the guidelines previously mentioned ${ }^{17,18}$. 


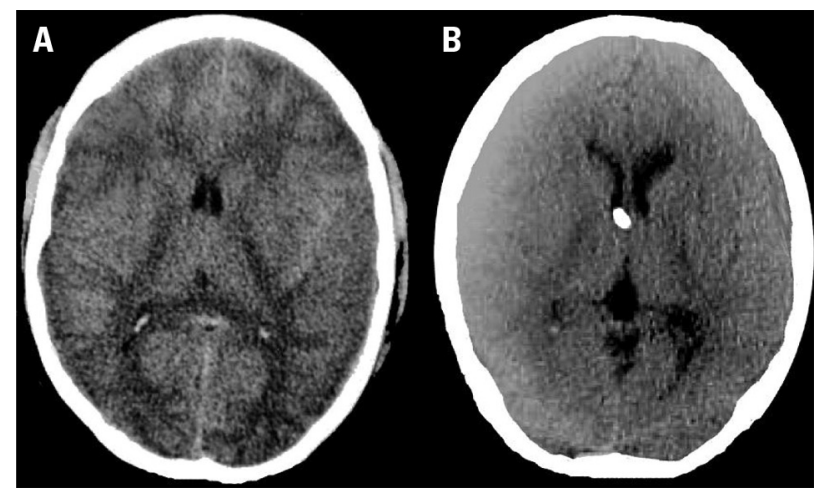

Fig 1. [A] CT scan depicting the posttraumatic diffuse injury (Type III - see text for details). [B] Postoperative aspect with intraventricular catheter.

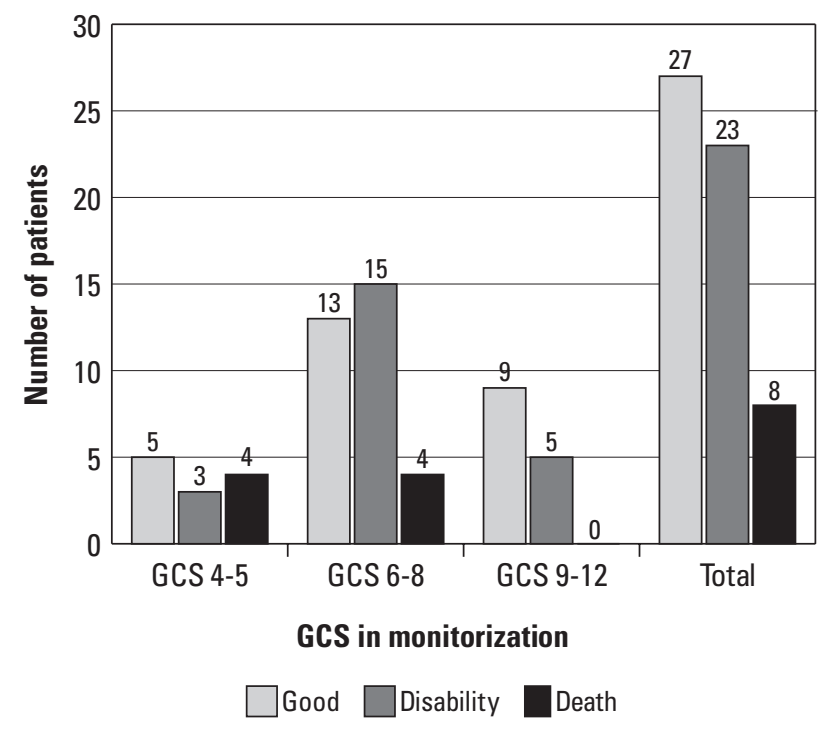

Fig 3. Graphic depicting the relationship between clinical outcome and GCS scores at the time of intraventricular monitoring.

No patient underwent hypothermia. Ceftriaxone (1g IV twice a day) was used routinely as infection prophylaxis.

\section{Statistical analysis}

Median values and standard deviation was obtained from all data. Groups by age were evaluated by the nonparametric test of Kruskal-Wallis. Statistical analyses were performed at 0.05 level of significance.

\section{RESULTS}

Eleven patients were 16 years old or younger and 47 older. Fifty-eight patients (48 male and 10 female) with average age of 29 years old (from 4 to 65 years old) were included in this study. Mechanisms of injury were respec-

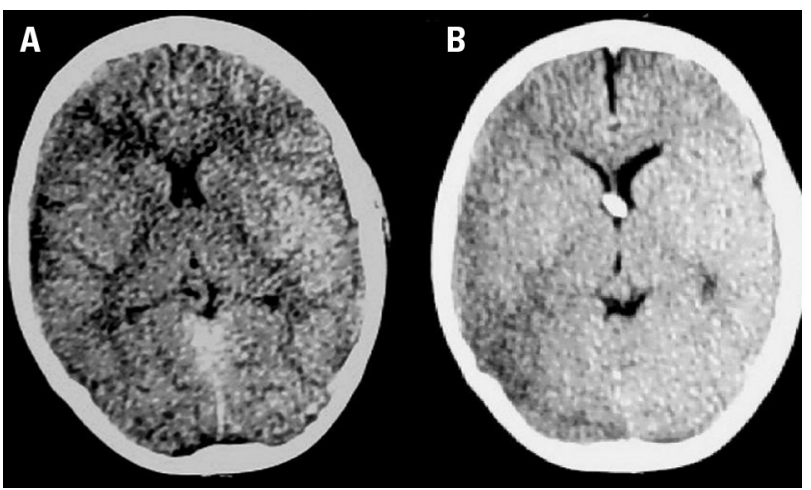

Fig 2. [A] Preoperative CT scan from a patient of the pediatric group depicting a Type III posttraumatic injury. [B] Postoperative CT scan. Sulci and cisterns may be now better visualized.

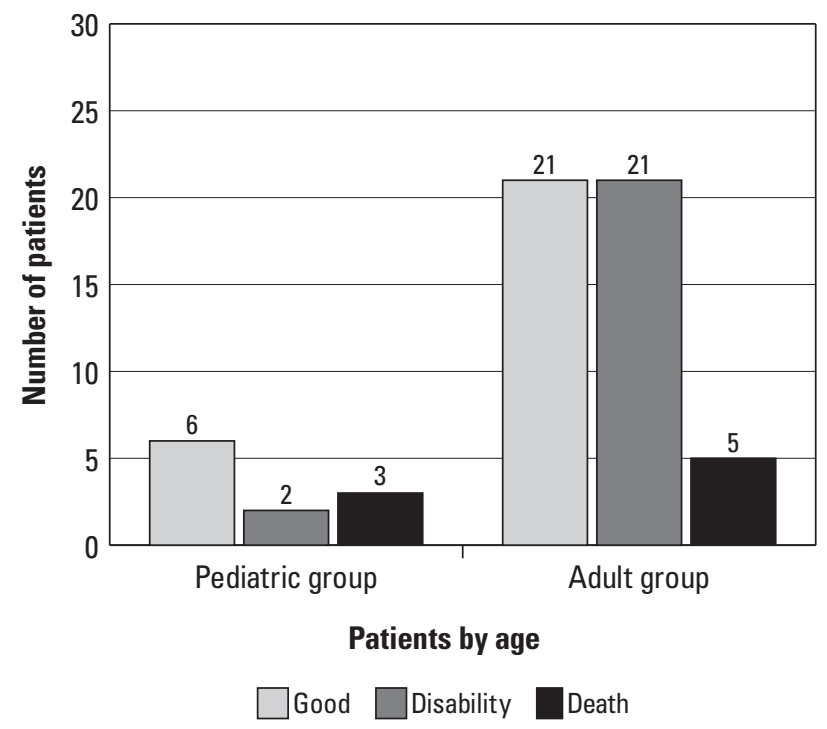

Fig 4. Graphic depicting clinical outcome by age group.

tively: 42 (72.4\%) motorized vehicle accidents, 9 (15.6\%) falls, $4(6.6 \%)$ assaults, and $3(5.1 \%)$ gunshots. Twelve (22.2\%) patients were monitored with scores between 4 and 5 at GCS, 32 (54\%) between 6 and 8, and 14 (23.8\%) between 9 and 12. Four (9.5\%) patients presented ICP over $15 \mathrm{mmHg}$ at the first measurement at ICU. All patients evolved to normal ICP values after a few days of continuous drainage and ICU therapy. We have not seen the collapse of the ventricle in any patient

Patients with GCS scores 4-6 (Group I) comprised $20.7 \%(n=12)$ of the total,

Whereas group II (GCS scores 6-8) and III (GCS scores 9-12) constituted 55.2\% $(\mathrm{n}=32)$ and $24.2 \%(\mathrm{n}=14)$. In the group I, five patients $(41.6 \%)$ had favorable out- 
come, three (25\%) unfavorable and 4 (33.3\%) deceased. In the group II, 13 (40.6\%) evolved favorably, 15 (46.8\%) unfavorably and $4(12.5 \%)$ to death. Among the patients in the group III, 9 (64.2\%) evolved favorably, 5 (35.7\%) unfavorably and none deceased (Fig 3).

There were no statistical differences, regarding outcome, between groups separated by age $(\mathrm{p}>0.05)$. In the children group (younger than 17) ( $\mathrm{n}=11$ ), six (54.5\%) presented favorable outcome, whereas five (45.5\%) evolved unfavorably. In the adults group ( $\mathrm{n}=47), 44.7 \%$ and $55.3 \%$ evolved favorably and unfavorably, respectively (Fig 4).

The overall rate of infection (ventriculites) was 8.3\%. Two of these patients with ventriculitis were victims of gunshot wound. Three patients (5.1\%) presented CSF infection diagnosed within the $5^{\text {th }}$ and $6^{\text {th }}$ days of ICP monitoring. None presented CSF infection before the fourth day of ICP monitoring. Two patients (3.4\%) presented ventriculitis in the $13^{\text {th }}$ and $25^{\text {th }}$ days respectively. They developed shunt dependent hydrocephalus and systemic infection, thus, intraventricular catheter needed to remain longer than 7 days. All cases revealed positive culture results (Klebisiella pneumoniae-1, Acinetobacter baumanii-3, Proteus mirabilis-1). CSF cell count never went over 500 cells $/ \mathrm{mm}^{3}$. Infection contributed neither to patient clinical worsening nor death ( $p>00.5)$. In this series there was no intracranial bleeding and no patient needed decompressive craniectomy.

\section{DISCUSSION}

Although there is no "class I" evidence, ICP monitoring is accepted worldwide as useful, if not essential, for management of severely head-injured patients. Intraventricular drain connected to an external pressure transducer is still considered to be a "golden standard" method because it provides the most reliable ICP value and offers the immediate treatment of elevated intracranial pressure by means of CSF drainage ${ }^{19,20}$, when compared with other methods ${ }^{21}$. It is noteworthy that intracranial optical sensors usually evolve with a drift in calibration that may difficult the evaluation of ICP measurements ${ }^{22}$.

In patients with reduced intracranial compliance, intermittent or continuous drainage of CSF through a ventriculostomy catheter can be an effective means of controlling ICP and may constitute an alternative to an early decompressive craniectomy ${ }^{23}$.

Other authors associate lumbar drainage with intraventricular drainage in order to improve ICP lowering ${ }^{24}$. Several neurosurgical centers around the world have used ventriculostomy catheters in patients with posttraumatic brain swelling. This methodology has been routinely used in our program since $2000^{17}$.

Various studies have indicated that CSF drainage may improve outcome of patients sustaining posttraumatic brain swelling 9 . A meta-analysis of 14 studies has suggested that the use of ventricular drainage lowered mortality rates in series which have routinely employed CSF drainage (21\%) when compared to those that had used it occasionally (35\%) or those which had never used $(43 \%)^{18}$. However, the non-randomized nature of these analyses must be kept in mind. In our study the overall mortality rate was $13,6 \%$ and mainly related to the GCS scores.

There is evidence that the ventricular system, when adequately vented, provides a sink for drainage of interstitial fluid associated with cerebral edema ${ }^{25}$. This way, interstitial fluid, which communicates with ventricular fluid, may be continuously drained through ventricular catheter. Additionally, high concentrations of proinflammatory chemokines, such as leukotriene $\mathrm{C} 4$ and interleukin-6, detected in the CSF following severe head injury may be reduced by the continuous CSF clearance ${ }^{10}$.

A study has demonstrated that intermittent drainage of CSF was associated with twofold greater CSF concentrations of markers of neuronal injury (neuron specific enolase), glial injury (s100B), inflammation (interleukin-6), and regeneration (vascular endothelial growth factor), and with about half the volume of CSF removal compared with continuous CSF drainage ${ }^{12}$. Therefore, continuous CSF drainage can lower levels of brain water not only by dehydration of swollen brain but also by reducing both the duration and intensity of the posttraumatic brain inflammatory process. These effects may play a beneficial role in a tissue that presents a greater water/blood volume content ratio ${ }^{26,27}$. As a result; decreased level of ICP might be expected if continuous CSF drainage is employed. In our study, all patients underwent continuous CSF drainage and intracranial hypertension was found in only $4 \mathrm{pa}$ tients during their stay in intensive care unit. Nonetheless, continuous CSF drainage was able to definitely control the ICP in all patients. Brain swelling with collapsed ventricles has been cited as a hurdle for ICP monitoring as it decreases availability of CSF to be drained ${ }^{28}$. In cases where ventricular cavity is not reached by a catheter after two free-hand attempts, other means of ICP monitoring are indicated. Sometimes, use of frameless stereotactic system to position ventricular catheter may facilitate the procedure and avoid complications.

Ventricular catheters are associated with risk of infection, and less frequently, with intracranial hemorrhage. It is has been demonstrated that the risk of infection increases after five days of ventriculostomy catheter placement, with an overall risk estimated $8.6 \%-11 \%^{28-32}$. Conversely, a study has reported that the length of ICP monitoring does not influence the infection rate and, therefore, the decision to keep the catheter should be based solely on the need for ICP control ${ }^{33}$. On the other hand, $2 \%$ of patients without ventriculostomy may develop meningi- 
tis after severe traumatic brain injury $(\mathrm{TBI})^{1}$. Infections are not usually seen in patients monitored for 3 days or less in most series. In our protocol, ventricular catheters were withdrawn on the seventh day after their placement, except in two patients with shunt-dependent hydrocephalus. Eight patients remained with ventricular catheter longer than seven days due to CSF infection (3 patients) or presence of shunt-dependent hydrocephalus concomitantly with systemic or CSF infection (2 patients). The overall infection rate was $8.6 \%$ but $5.2 \%$ occurred within 5 days following the ventricular catheterization. Two of these patients with ventriculitis were victims of gunshot wound, we believe that this condition has contributed to the proportion of infection. Reports of risk of intracranial hemorrhage as the second cause of morbidity after catheter placement varies from 1 to $2 \%$. It is more commonly found in patients with coagulopathies. In the current series there was no instance of clinically significant intracerebral bleeding associated to ICP monitoring.

In our study, 27 patients (46.5\%) presented favorable neurological outcome, and 31 patients (53.5\%) unfavorable outcome. Mortality rate was $13.7 \%$ (8 patients). We believe the mortality of these patients were not the result of intracranial hypertension, whereas in only 6 patients was verified intracranial hypertension, being corrected by clinical measures. Intermittent monitoring every hour would allow us to detect any moments of intracranial hypertension before generating the patient's death. We verified eight deaths; four of these patients had very serious TBI with 4 points in Glasgow Coma Scale. We believe that the deaths are related to the severity of brain injury.

In our study, we verified 5 (35.7\%) unfavorably in Group III, we believe the inclusion of two patients with brain swelling and injury by firearms in this group have contributed to the negative numbers in this group. All patients (5) with unfavorable outcome had Glasgow Coma scale score 9 . We believe that monitoring in patients with moderate TBI who have cerebral swelling is an important management option, considering the incidence of neurological worsening and life-threatening, particularly in patients with nine points in Glasgow Coma Scale. Additionally continuous drainage was able to control ICP and no decompressive craniectomy was necessary. The result of our study on use of continuous CSF drainage in traumatic brain swelling is encouraging as a method of choice for management of this condition, and indicates a need for randomized trials directly comparing it with other methods.

In conclusion, our results demonstrated that continuous ventricular CSF drainage with ICP monitoring is a simple, safe and feasible method to manage most of patients with diffuse posttraumatic brain swelling. This study contributes to the literature revisiting continuous
CSF ventricular drainage and ICP monitoring as a manner to treat intracranial hypertension in posttraumatic bihemispheric brain swelling. A randomized and well-controlled trial is required to prove effectiveness of this surgical technique when compared with either intermittent CSF drainage or non-surgical management.

\section{REFERENCES}

1. Luerssen TG, Chesnut RM, Van Berkum-Clark M. Post traumatic cerebrospinal fluid infection in the Traumatic Coma Data Bank: the influence of type and management of monitoring. In: Avezaat CCJ, van Eijndhoven JHM, Maas AIR (Eds). Intracranial Pressure VIII. Berlin: Springer Verlag, 1991:42-45.

2. Toutant SM, Klauber MR, Marshall LF, et al. Absent or compressed basal cisterns on first CT scan: ominous predictors of outcome in severe head injury. J Neurosurg 1984;61:691-694.

3. Bor-Seng-Shu E, Hirsch R, Teixeira MJ, Andrade AF, Marino Jr R. Cerebral hemodynamic changes gauged by transcranial Doppler sonograph in patients with posttraumatic brain swelling treated by surgical decompression. J Neurosurg 2006;104:93-100.

4. Wagner S, Schnippering H, Aschoff A, Koziol JA, Schwab S, Steiner T. Suboptimum hemicraniectomy as a causa of additional cerebral lesions in patients with malignant infartation of the middle crebral artery. J Neurosurg 2001;94:693-696.

5. Gopinath SP, Robertson CS, Contant CF, Narayan RK, Grossman RG. Clinical evaluation of a miniature strain-gauge transducer for monitoring intracranial pressure. Neurosurgery 1995;36:1137-1140.

6. Koskinen LD, Olivercrona M. Clinical experience with the intraparechymal intracranial pressure monitoring Codman microsensor system. Neurosurgery 2005;56:693-698.

7. Piper I, Barnes A, Smith D, Dunn L. The Camino intracranial pressure sensor: is it optimal technology? An internal audit with a review of current intracranial pressure monitoring technologies. Neurosurgery 2001;49:1158-1165.

8. Cao M, Lisheng $\mathrm{H}$, Shouzheng $\mathrm{S}$. Resolution of brain edema in severe brain injury at controlled high and low intracranial pressures. J Neurosurg 1984; 61:707-712.

9. Caruselli G, Recchioni MA, Occhipinti C, Bernardini M, Caruselli M. The role of CSF ventricular drainage in controlling intracranial hypertension in patients with brain lesions. Comparison of three methods. Preliminary results. J Neurosurg Sci 1992;36:219-225.

10. Ghajar JB, Hariri RJ, Patterson RH. Improved outcome from traumatic coma using only ventricular CSF drainage for ICP control. Adv Neurosurg 1993; 21:173-177.

11. Papo I, Caruselli G, Luongo A. CSF withdrawal for the treatment of intracranial hypertension I acute head injuries. Acta Neurochirurgica 1981;56:191-199.

12. Shore PM, Thomas NJ, Clark RS, et al. Continuous versus intermittent cerebrospinal fluid drainage after severe traumatic brain injury in children: effect on biochemical markers. J Neurotrauma 2004;21:1113-1122.

13. American College of Surgeons. ATLS student manual. $8^{\text {th }}$ ed, Chicago: ACS, 2007

14. Marshall LF, Marshall SB, Klauber MR, et al. The diagnosis of head injury requires a classification based on computed axial tomography. J Neurotrauma. 1992;9 (Suppl 1):S287-S292.

15. Park P, Garton HJL, Kocan MJ, Thompson BG. Risk of infection with prolonged ventricular catheterization. Neurosurgery 2004;55:594-601.

16. Kanter MJ, Narayan RK. Management of head injury. Intracranial pressure monitoring. Neurosurg Clin N Am 1991;2:257-265.

17. Andrade AF, Marino Jr R, Miura FK, Brock RS, Ciquini O, Pinto FCG. Preliminary experience with decompressive ventriculostomy by continuous ventricular cerebrospinal fluid drainage in posttraumatic diffuse brain swelling. J Neurotrauma 2000;19:1381

18. Bullock R, Chesnut RM, Clifton G, et al. Guidelines for the management of severe head injury: Brain Trauma Foundation. J Neurotrauma 1996;13: 639-734.

19. Czosnyka M, Pickard JD. Monitoring and interpretation of intracranial pressure. J Neurol Neurosurg Psychiatry 2004;75:813-821.

20. Narayan RK, Kishore PR, Becker DP, et al. Intracranial pressure: to monitor or not to monitor? A review of our experience with severe head injury. J Neurosurg 1982;56:650-659.

21. Feldman Z, Narayan RK. Intracranial pressure monitoring techniques and 
pitfalls. In: Cooper PR (Ed). Head injury $3^{\text {rd }}$ Ed. Baltimore: Williams\&Wilkins, 1993:247-274.

22. Chesnut RM, Marshall LF, Marshall SB. Medical management of intracranial pressure. In: Cooper PR (Ed). Head Injury. 3a ed. 1993; 225-246.

23. Andrade AF, Marino Jr R, Ciquini O, Figueiredo EG, Machado AG. Guidelines for neurosurgical trauma in Brazil. World J Surg 2001;25:1186-1201.

24. Levy DL, Rekate HL, Cherny WB, Manwaring K, Moss D, Baldwin HZ. Controlled lumbar drainage in pediatric head injury. J Neurosurg 1995;83: 453-460.

25. Hariri RJ. Cerebral edema. Neurosurg Clin North America 1994;5:687-706.

26. Marmarou A, Fatouros PP, Barzo P, et al. Contributions of edema and cerebral blood volume to traumatic brain swelling in head injured patients. J Neurosurg 2000;93:183-193.

27. Reulen HJ, Tsuyumu M, Tack A, Fenske AR, Prioleau GR. Clearance of edema fluid into cerebral spinal fluid. A mechanism for resolution of vasogenic brain edema. J Neurosurg 1978;48:754-764.
28. Flibotte JJ, Lee KE, Koroshetz WJ, Rosand J, McDonald CT. Continuous antibiotic prophylaxis and cerebral spinal fluid infection in patients with intracranial pressure monitors. Neurocrit Care 2004;1:61-68.

29. Holloway KL, Barnes T, Choi S, et al. Ventriculostomy infectons: the effect of monitoring duration and catheter exchange in 584 patients. J Neurosurg 1996;85:419-424.

30. Mayhall CG, Archer NH, Lamb VA, et al. Ventriculostomy-related infections. A prospective epidemiologic study. N Engl J Med 1984;310:553-559.

31. Rebuck JA, Murry KR, Rhoney DH, Michael DB, Coplin WM. Infection related to intracranial pressure monitors in adult: analysis of risk factors and antibiotic prophylaxis. J Neurol Neurosurg Psychiatry 2000;69:381-384.

32. Blaha M, Lazar D. Traumatic brain injury and hemorrhagic complications after intracranial pressure monitoring. J Neurol Neurosurg Psychiatry 2005; 76:147.

33. Winfield JA, Rosenthal P, Kanter RK, Casella G. Duration of intracranial pressure monitoring does not predict daily risk of infectious complications. Neurosurgery 1993; 33:424-431. 